\title{
Pengaruh Penambahan Ekstrak Cabai Merah (Capsicum annuum L.) terhadap Kadar Nitrit pada Sosis di Kota Surakarta dengan Spektrofotometer UV-Vis
}

\author{
The Influence of Adding Red Chilli Extract (Capsicum annuum L.) to Nitrit Levels on Sausage at Surakarta \\ with Spektrofotometer \\ Wimpy, Tri Harningsih* \\ Sekolah Tinggi Ilmu Kesehatan Nasional Surakarta \\ *Corresponding author: tri.harningsih@gmail.com
}

\begin{abstract}
ABSTRAK
Makanan cepat saji sudah menjadi pilihan bagi kebanyakan masyarakat di Indonesia. Fakta menunjukkan lebih dari 33\% masyarakat Indonesia setiap hari mengkonsumsi makanan cepat saji karena pelayanan cepat,dan harga murah. Makanan cepat saji tidak dapat dikategorikan sebagai makanan sehat. Konsumen sering memesan makanan ini dengan kandungan lemak, kalori, gula, sodium yang banyak dan sedikit mengandung nutrisi serta vitamin. Nitrit seringkali ditambahkan dalam proses pembuatan sosis sebagai bahan pengawet, bahan tersebut diketahui sebagai penyebab penyakit kanker. Tujuan dari penelitian ini untuk mengetahui pengaruh penambahan ekstrak cabai merah (Capsicum annum L.) yang optimal untuk menurunkan kadar nitrit pada sosis di kota Surakarta dengan Spektrofotometer UV-Vis. Penelitian ini telah selesai dilakukan di laboratorium Makanan dan Minuman Sekolah Tinggi Ilmu Kesehatan Nasional pada bulan Oktober sampai Desember 2016. Terdapat 6 sampel sosis tidak bermerk yang berasal dari 3 pasar di Surakarta dan data diambil menggunakan teknik Quota Sampling. Sampel sosis dengan penambahan ekstrak cabai merah menggunakan variasi konsentrasi 0\%, 25\%, 50\%, 75\%, 100\%. Analisa menggunakan instrument Spektrofotometer AES-80 untuk menentukan kadar nitrit pada sosis. Hasil pengukuran kadar nitrit yaitu pada konsentrasi 0\% kadar nitrit sebesar 33,459ppm; konsentrasi 25\% sebesar 12,239ppm; konsentrasi 50\% sebesar 11,070ppm, konsentrasi 75\% sebesar 5,699 ppm dan konsentrasi 100\% sebesar 3,935 ppm. Berdasarkan uji regresi linier menunjukkan hasil signifikan 0,044 yang menunjukkan bahwa ada perbedaan signifikan karena nilai sig. $<\alpha(0,05)$, maka ada pengaruh penambahan vitamin C terhadap kadar nitrit pada sosis di kota Surakarta.
\end{abstract}

Kata kunci: ekstrak cabai, kadar nitrit, sosis, quota sampling

\section{ABSTRACT}

Fast food seems like the ideal "all-Indonesian" choice. In fact, over 33 percent of Indonesian's consume fast food every day because it is efficient service and low prices. Fast food does not have to be unhealthy. Consumers often order fast foods with more fat, calories, sugar, sodium, and less nutrition and vitamins than is necessary. One of the fast food that is so common in Indoneisa is sausage. Nitrit is often added during sausage processing as a preservative, which are known to cause cancer. The purpose of this research is to find out the influence of adding red chilli extract (Capsicum annuum L.) to nitrit levels on sausage at Surakarta analysis with spectrophotometer UV-Visible. This research has been done in Laboratory of Food and Drink Analysis of Sekolah Tinggi Ilmu Kesehatan Nasional Surakarta during OctoberDecember 2016. There are 6 samples of unbranded sausages from the 3 markets in Surakarta that has been collected with Quota Sampling Technique. The sausages samples are added with red chilli extract with many variation of concentration $0 \%, 25 \%, 50 \%, 75 \%$ and $100 \%$. This analized use Spectrophotometer AES-80 to determine the nitrit levels on sausages. The results are nitrit levels on 0\% concentration are 33,459 ppm; 25\% concentration are 12,359 ppm; 50\% concentration are 11,070 ppm; 75\% concentration are 5,699 ppm; and 100\% concentration are 3,935 ppm. Based on Regression Linier Statistic test on sausage sample that's been added with red chilli extract get significant value 0,044. There is significant difference of nitrit levels after it has been added with red chilli extract.

Keyword: chilli extract, nitrit levels, sausage, quota sampling.

\section{PENDAHULUAN}

Sosis yang merupakan makanan yang tidak hanya digemari anak-anak, melainkan remaja dan dewasa bahkan orang tua ini diperoleh dari produk olahan daging sapi yang mempunyai nilai gizi tinggi, yang berbentuk silindris dengan 
panjang kira-kira $8 \mathrm{~cm}-10 \mathrm{~cm}$. Industri pengolah daging yang terus berkembang maka aplikasi penggunaan bahan tam-bahan pangan semakin meningkat (Nurihanah, 2013).

Bahan tambahan pangan yang biasanya ditambahkan dalam makanan siap saji seperti sosis yaitu berupa pengawet. Pengawet yang diijinkan dalam proses pengawetan daging untuk memperoleh warna yang baik dan mencegah pertumbuhan mikroba yaitu nitrit. Badan Pengawas Obat dan Makanan (BPOM) RI No. 036 tahun 2013 tentang batas maksimum penggunaan bahan tambahan pangan pengawet menyatakan bahwa, mengijinkan penggunaan nitrit dalam produk olahan daging dengan batasan maksimum nitrit $30 \mathrm{mg} / \mathrm{kg}$ bahan.

Proses pengawetan, nitrit akan membentuk nitro oksid yang akan bereaksi dengan pigmen mioglobin membentuk nitrosomioglobin yang berwarna merah cerah. Nitrit tersebut bereaksi dengan amina, dan amina akan membentuk turunan nitrosamin yang bersifat karsinogenik yang dapat menyebabkan kanker (Restu, et. al., 2013). Adapun cara untuk menghambat pembentukan senyawa nitrosamin, salah satu contohnya yaitu dengan penggunaan asam askorbat (vitamin C) (Ermawati, 2008).

Asam askorbat mampu mem-percepat proses pembentukan nitrit oksida dari nitrit sehingga nitrit oksida ini akan bereaksi dengan mioglobin sehingga terbentuk warna merah muda (Ermawati, 2008). Salah satu sumber asam askorbat alami adalah berasal dari cabai merah (Capsicum annuum L.).

Cabai merah (Capsicum annuum L.) ini merupakan tanaman yang tidak asing bagi telinga masyarakat di Indonesia. Cabai merah (Capsicum annuum L.) merupakan jenis tanaman hortikultura yang cukup banyak ditanam di Indonesia yang memiliki nilai ekonomi dan permintaan yang cukup tinggi. Produksi cabai merah (Capsicum annuum L.) pada tahun 2015 sebanyak 5.165 ton yang berasal dari seluruh daerah di Indonesia dengan total kebutuhan mencapai
2.830 ton (Badan Ketahanan Pangan, 2015).

Vitamin $\mathrm{C}$ yang terkandung dalam cabai merah menurut Departemen Kesehatan RI tahun 1981 tentang Kandungan dan Nilai Gizi Buah dan Sayur- sayuran adalah $50 \mathrm{mg} / 100$ gram. Tujuan penggunaan cabai merah sebagai sumber vitamin $C$ (asam askorbat) memungkinkan untuk mempercepat pem- bentukan nitrit oksid sehingga dapat menurunkan kadar nitrit sebagai pengawet dalam makanan siap saji (sosis). Kadar nitrit dapat ditentukan dengan menggunakan metode spektrofotometri.

Metode spektrofotometri ini dapat digunakan untuk menetapkan kadar natrium nitrit dalam sosis olahan daging. Penentuan senyawa pengawet didasarkan pada reaksi gugus fungsi yang terdapat di dalam bahan pengawet dengan zat kimia tertentu (indikator) yang dapat menghasilkan senyawa berwarna yang dapat ditentukan dengan UV-Vis (Lestari, et. al., 2011).

Berdasarkan latar belakang diatas, penulis memiliki tujuan yang ingin dicapai dalam penelitian ini adalah 1). Untuk mengetahui ada tidaknya kandungan nitrit pada sosis di kota Surakarta. 2). Untuk mengetahui pengaruh penambahan ekstrak cabai merah (Capsicum annuum L.) terhadap kadar nitrit pada sosis di kota Surakarta dengan Spektrofotometer UV-Vis 3). Untuk mengetahui konsentrasi ekstrak cabai merah ( $\mathrm{Cap}$ sicum annuum L.) yang optimal untuk menurunkan kadar nitrit pada sosis di kota Surakarta dengan Spektrofotometer UV-Vis.

\section{METODE PENELITIAN}

\section{Waktu dan Lokasi Penelitian}

Penelitian dilaksanakan pada bulan Oktober 2016 sampai bulan Desember 2016 di Laboratorium Analisa Makanan dan Minuman Sekolah Tinggi Ilmu Kesehatan Nasional Surakarta.

\section{Bahan}

Sosis sapi, Cabai Merah, Asam Askorbat, Natrium Nitrit, $\mathrm{KI}, \mathrm{HCl}$, Asam Sulfanilat, Naftilamin, Etanol $70 \%, \mathrm{Na}_{2} \mathrm{~S}_{2} \mathrm{O}_{3}, \mathrm{KIO}_{3} 0,1 \mathrm{~N}, \mathrm{H}_{2} \mathrm{SO}_{4}$, 
$\mathrm{I}_{2}$, Aquabides.

\section{Cara kerja}

\section{Pembuatan ekstrak cabai merah}

Serbuk cabai merah sebanyak 20 gram dimasukkan ke dalam maserator (gelas bejana tertutup) lalu ditambahkan pelarut etanol 70\% sebanyak $200 \mathrm{ml}$, simpan suhu kamar hingga 5 hari kemudian disaring. Ampas diremaserasi lagi dengan prosedur yang sama selama 2 hari (Padma sari, dkk., 2014). Disaring, ambil filtrat dikentalkan dengan rotary evaporator (Warsi, dkk., 2013).

\section{Uji Kualitatif Kadar Nitrit (Vogel, 1985)}

1) Lima gram sampel sosis tambahkan aquabides $15 \mathrm{~mL}$. Disaring ambil filtrat sebanyak $2 \mathrm{~mL}$ tambah 1 tetes asam sulfanilat dan 1 tetes naftilamin. Positif terdapat nitrit jika terbentuk warna merah

2) Lima gram sampel sosis tambahkan aquabides $15 \mathrm{~mL}$. Disaring ambil filtrat sebanyak $2 \mathrm{~mL}$ tambah 1 tetes KI, 1 tetes $\mathrm{HCl}$, dan 1 tetes amilum. Positif terdapat nitrit jika terbentuk warna ungu.

\section{Uji Kuantitatif Kadar Nitrit dengan Spektro- fotometer $U V$-Vis}

\section{1) Pembuatan Larutan Griess}

Mencampur larutan I dan larutan II dengan perbandingan 50:50 dalam wadah botol berwarna coklat. Larutan I disiapkan dengan melarutkan 0,5 gram asam sulfanilat dalam $150 \mathrm{~mL}$ asam asetat 30\% v/v. Larutan II disiapkan dengan mendidihkan 0,1 gram naftilendiamin dalam $20 \mathrm{~mL}$ aquabidestilata sampai larut dan menuangkannya dalam keadaan panas ke dalam $150 \mathrm{~mL}$ asam asetat glasial (Rohman dan Sumantri, 2007).

\section{2) Pembuatan Larutan Baku Nitrit}

Ditimbang sebanyak 100 mg $\mathrm{NaNO}_{2}$ kemudian dilarutkan dalam aqua bidestilata sampai volumenya tepat $100 \mathrm{ml}$ hingga diperoleh konsentrasi 1000 ppm (Cunniff, 1995).

\section{3) Pembuatan Seri Konsentrasi Baku Nitrit}

Dari larutan baku 1000 ppm dipipet 1; 1,4; 1,$8 ; 2,2 ; 2,6 ; 3 ; 3,5 ; 4,2 ; 5,4 \mathrm{~mL}$ dan diencerkan dengan aqua bidestilata sampai volumenya tepat $100 \mathrm{~mL}$ sehingga diperoleh seri konsentrasi 1; 1,$4 ; 1,8 ; 2,2 ; 2,6 ; 3 ; 3,5 ; 4,2 ; 5,4$ ppm (Lestari, dkk., 2011).

\section{4) Penentuan Panjang Gelombang Maksimum}

Larutan baku natrium nitrit konsentrasi 15 ppm, diambil $10 \mathrm{ml}$ dan ditambah $2 \mathrm{~mL}$ pereaksi Griess kemudian dibaca absorbansinya pada panjang gelombang 500 - $560 \mathrm{~nm}$. Diperoleh panjang gelombang yang memberikan absorbansi maksimum (Lestari, dkk., 2011).

\section{5) Operating Time}

Larutan baku natrium nitrit konsentrasi 15 ppm, diambil $10 \mathrm{~mL}$ dimasukkan dalam enam tabung reaksi dan masing-masing ditambah $2 \mathrm{~mL}$ pereaksi Griess kemudian dibaca absorbansinya pada panjang gelombang max setiap 3, 6, 9, 12, 15, dan 18 menit. Ditentukan operating timenya (Lestari, dkk., 2011).

\section{6) Pembuatan Kurva Baku Nitrit}

Larutan baku natrium nitrit dengan konsentrasi $1 ; 1,4 ; 1,8 ; 2,2 ; 2,6 ; 3 ; 3,5 ; 4,2 ; 5,4$ ppm, masing-masing diambil $10 \mathrm{~mL}$ dan ditambahkan $2 \mathrm{~mL}$ pereaksi Griess. Larutan dibiarkan selama operating time kemudian dibaca absorbansinya dengan menggunakan spektrofotometer Uv-Vis pada panjang gelombang max.

\section{Titrasi Iodimetri pada Sampel Cabai Merah} (Karinda, dkk., 2013)

1) Standarisasi larutan $\mathrm{Na}_{2} \mathrm{~S}_{2} \mathrm{O}_{3}$ dengan larutan $\mathrm{KIO}_{3} 0,1 \mathrm{~N}$.

Dipipet $10 \mathrm{~mL}$ larutan $\mathrm{KIO}_{3}$ 0,1 N. Setelah itu, ditambahkan $5 \mathrm{~mL}$ larutan KI 10\%, lalu ditambahkan $2 \mathrm{~mL}$ larutan $\mathrm{H}_{2} \mathrm{SO}_{4}$ dan dititrasi dengan larutan $\mathrm{Na}_{2} \mathrm{~S}_{2} \mathrm{O}_{3}$ sampai berwarna kuning muda. Selanjutnya ditam- bahkan beberapa tetes larutan amilum 1\% lalu dititrasi lagi dengan larutan $\mathrm{Na}_{2} \mathrm{~S}_{2} \mathrm{O}_{3}$ sampai warna biru hilang.

2) Standarisasi larutan $I_{2}$ dengan larutan standar $\mathrm{Na}_{2} \mathrm{~S}_{2} \mathrm{O}_{3} 0,03 \mathrm{~N}$. 
Dipipet $10 \mathrm{~mL}$ larutan $\mathrm{I}_{2}$, lalu dititrasi dengan larutan $\mathrm{Na}_{2} \mathrm{~S}_{2} \mathrm{O}_{3}$ sampai warna kuning muda. Kemudian ditambahkan beberapa tetes larutan amilum, selanjutnya dititrasi dengan larutan $\mathrm{Na}_{2} \mathrm{~S}_{2} \mathrm{O}_{3}$ sampai warna biru hilang.

\section{3) Penetapan kadar vitamin $\mathrm{C}$ dalam larutan}

\section{sampel dengan larutan Iodium standar.}

Dipipet $50 \mathrm{~mL}$ larutan sampel cabai merah, lalu dimasukkan kedalam erlenmeyer. Kemudian ditambahkan $6 \mathrm{~mL}$ larutan $\mathrm{H}_{2} \mathrm{SO}_{4} 10 \%$, ditambahkan beberapa tetes larutan amilum $1 \%$ dan dititrasi dengan larutan $I_{2}$ standar sampai berwarna biru. Kemudian membuat larutan vitamin $\mathrm{C}$ dari asam askorbat murni sesuai hasil titrasi kadar vitamin $\mathrm{C}$ pada cabai merah.

\section{Penetapan Kadar Nitrit pada Sosis}

Sebanyak $5 \mathrm{~g}$ sampel (sosis sapi) ditimbang secara seksama dan dihaluskan, kemudian dilakukan penambahan larutan extrak cabai merah dengan konsentrasi $0 \%, 25 \%, 50 \%, 75 \%, 100 \%$, dimasukkan dalam labu takar $50 \mathrm{~mL}$. Sampel selanjutnya ditambah dengan aqua bidestilata yang telah dipanaskan pada suhu $80^{\circ} \mathrm{C}$ lalu diaduk dengan pengaduk kaca. Sebanyak $5 \mathrm{~mL}$ larutan hasil penyaringan dipipet lalu dimasukkan ke dalam labu takar $10 \mathrm{~mL}$, diencerkan dengan aqua bidestilata sampai batas tanda dan ditambah $2 \mathrm{~mL}$ pereaksi Griess. Larutan dibiarkan selama operating time dan dibaca absorbansinya pada panjang gelombang max (Lestari, et. al., 2011).

\section{HASIL DAN PEMBAHASAN \\ Uji kualitatif kadar nitrit}

Hasil uji kualitatif kadar nitrit pada sosis ditunjukkan pada Tabel 1.

Keterangan :

a. Uji kualitatif dengan pereaksi asam sulfanilat dan naftilamin hasil positif mengandung nitrit ditunjukkan dengan terbentuknya warna merah.

b. Uji kualitatif dengan pereaksi $\mathrm{KI}$ dan $\mathrm{HCl}$ hasil positif mengandung nitrit ditunjukkan dengan terbentuknya warna ungu.

Uji kualitatif menunjukkan hasil positif mengandung nitrit pada seluruh sampel sosis, maka dari itu dilanjutkan dengan uji kuantitatif dari sampel sosis dengan penambahan ekstrak cabai merah dengan variasi konsentrasi.

Hasil uji kuantitatif kadar nitrit pada sosis ditunjukkan pada Tabel 2.

Grafik hasil pemeriksaan kadar nitrit dengan beberapa konsentrasi vitamin $\mathrm{C}$ ditunjukkan pada Gambar 1.

Tabel 1. Hasil Uji Kualitatif Kadar Nitrit Pada Sosis

\begin{tabular}{cccc}
\hline No. & $\begin{array}{c}\text { Kode } \\
\text { Sampel }\end{array}$ & $\begin{array}{c}\text { Reaksi } \\
\text { dengan } \\
\text { asam } \\
\text { sulfanilat } \\
\text { dan } \\
\text { naftilamin }\end{array}$ & $\begin{array}{c}\text { Reaksi } \\
\text { dengan } \\
\text { kalium } \\
\text { odida dan } \\
\text { HCl }\end{array}$ \\
\hline 1. & Sosis A & Positif & Positif \\
2. & Sosis B & Positif & Positif \\
3. & Sosis C & Positif & Positif \\
4. & Sosis D & Positif & Positif \\
5. & Sosis E & Positif & Positif \\
6. & Sosis F & Positif & Positif \\
\hline
\end{tabular}

Tabel 2. Hasil Uji Kuantitatif Kadar Nitrit Pada Sosis

\begin{tabular}{clcc}
\hline No. & $\begin{array}{c}\text { Konsentrasi } \\
\text { Vit. C }\end{array}$ & Abs & $\begin{array}{c}\text { Kadar } \\
\text { Nitrit } \\
\text { (ppm) }\end{array}$ \\
\hline 1. & Kons 0\% & 1,3391 & 33,459 \\
2. & Kons 25\% & 0,5667 & 12,359 \\
3. & Kons 50\% & 0,5195 & 11,070 \\
4. & Kons 75\% & 0,3229 & 5,699 \\
5. & Kons 100\% & 0,2583 & 3,935 \\
\hline
\end{tabular}




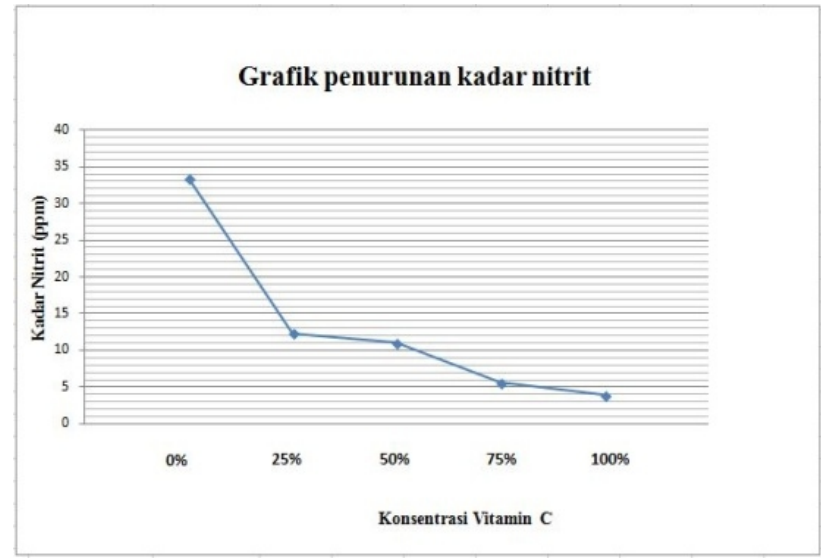

Gambar 1. Grafik Penurunan Kadar Nitrit dengan Penambahan Vitamin C

Berdasarkan hasil yang didapat kemudian data di uji statistik secara deskriptif, hasil yang didapatkan nilai Standart Error < nilai Standart Deviation yaitu $5,332917<11,924764$ hal ini menunjukkan bahwa presisi dan akurasi baik maka data bisa dikatakan tepat dan teliti sehingga data dapat dilanjutkan uji selanjutnya.

Data selanjutnya di uji normalitas dengan uji Shapiro-Wilk menunjukkan hasil signifikan sebesar 0,095 adalah lebih dari 0,05 maka data terdistribusi normal. Kemudian data dapat diuji menggunakan uji regresi linier menunjukkan hasil signifikan 0,044 yang menunjukkan bahwa ada perbedaan signifikan karena nilai sig. $<\alpha(0,05)$, maka ada pengaruh penambahan vitamin $\mathrm{C}$ terhadap kadar nitrit pada sosis di kota Surakarta.

Adanya zat pereduksi seperti asam askorbat mampu menurunkan kadar nitrit, karena asam askorbat akan mempercepat reduksi nitrit menjadi nitrit oksid, sehingga nitrit oksid bereaksi dengan metmioglobin menjadi nitrosomet-mioglobin, kemudian mengalami proses reduksi menjadi nitrosomioglobin yang berwarna merah cerah.

Oleh sebab itu, nitrit yang banyak terkandung di dalam makanan siap saji seperti sosis dapat menyebabkan keracunan, kesulitan bernafas, sakit kepala, anemia, juga radang ginjal (Aji, 2012).

\section{SIMPULAN DAN SARAN Kesimpulan}

1) Terdapat kandungan nitrit pada seluruh sam- pel sosis.

2) Ada pengaruh penambahan vitamin $\mathrm{C}$ terhadap kadar nitrit pada sosis di kota Surakarta.

3) Sampel yang ditambah vitamin $\mathrm{C}$ dengan konsentrasi 25\% dapat menurunkan kadar nitrit lebih banyak.

\section{Saran}

Kepada peneliti selanjutnya, perlu dilakukan uji lebih lanjut mengenai senyawa lain yang terkandung dalam cabai merah selain vitamin $\mathrm{C}$ yang berfungsi dalam penurunan nitrit.

\section{DAFTAR PUSTAKA}

Aji, D. 2012. Analisis Makanan Natrium Nitrit Sebagai Pengawet Makanan. Fakultas Farmasi, Universitas Pancasila. Jakarta.

Badan Ketahanan Pangan. 2015. http://bkp.pertanian.go.id/ diakses pada tanggal 10 Agustus 2015 pukul 23.12.

Cunniiff, P. 1995. Official Methode Of Analysis 16th Edition Volume 11. Gaitherburg, Maryland: AOAC International.

Departemen Kesehatan Republik Indonesia Tahun 1981. Kandungan dan Nilai Gizi Buah dan Sayur-Sayuran. Jakarta.

Ermawati, D. 2008. Pengaruh Penggunaan Ekstrak Jeruk Nipis (Citrus aurantifolia Swingle) Terhadap Residu Nitrit Daging Curing Selama Proses Curing. Skripsi. Fakultas Pertanian, Universitas Sebelas Maret. Surakarta.

Karinda, M., Fatimawali, \& Gayatri. 2013. Perbandingan Hasil Penetapan Kadar Vitamin C Mangga Dodol Dengan Menggunakan Metode Spektrofotometri UV-Vis dan Iodometri. Jurnal Ilmiah Farmasi. UNSRAT. Manado.

Lestari, P., Sabikis., Iswati, P.U. 2011. Analisis Nitrit Secara Spektrofotometri Visible Dalam Daging Burger yang Beredar di Swalayan Purwokerto. Purwokerto. Fakultas Farmasi, Universitas Muhammadiyah Puwokerto. Vol.08(03).

Nurihanah, F. 2013. Fabrika Strip Tes Berbasis Reagen Asam Sulfanilat Dan $\alpha$-Naftilamin UntukAnalisis Pengawet Nitrit Pada Sampel Sosis Kaleng. Skripsi. Fakultas Farmasi, Universitas Jember. Jember.

Padmasari, P.D., Astuti, K.W., \& Warditiani, N.K. 2014. Skrining Fitokimia Ekstrak Etanol 70\% Rimpang Bangle (Zingiber 
purpureum Roxb.). Fakultas Metematika Dan Ilmu Pengetahuan Alam, Universitas Udayana.

Republik Indonesia. 2013. Peraturan Kepala Badan Pengawas Obat dan Makanan (BPOM) No. 36 Tahun 2013 tentang Batas Maksimum Penggunaan Bahan Tambahan Pangan Pengawet.

Restu, E., Andriani, M., \& Nurhartadi, E. 2013. Pengaruh Penambahan Bit (Beta vulgaris) Sebagai Pewarna Alami Terhadap Karakteristik Fisiokimia Dan Sensori Sosis Daging
Sapi. Jurusan Teknologi Hasil Pertanian, Fakultas Pertanian, Universitas Sebelas Maret. Surakarta.

Rohman, A dan Sumantri. 2007. Analisis Makanan. Yogyakarta: Gadjah Mada University Press.

Vogel. 1995. Buku Teks Analisis Anorganik Kualitatif Makro dan Semimikro Bagian II. Jakarta: PT. Kalman Media Pustaka.

Warsi, \& Any, G. 2013. Aktivitas Antioksidan Ekstrak Metanol Buah Paprika Hijau (Capsicum annuum L.). Jurnal Ilmiah Kefarmasian. Vol.3, No.1. 